\title{
Flexible Dosing of Trospium Chloride for the Treatment of OAB - Results of a Non-Interventional Study in 4,092 Patients
}

\author{
A. Wiedemann ${ }^{1, \S}$, W. Kusche ${ }^{2, \S}$ and C. Neumeister ${ }^{*}, 3$ \\ ${ }^{I}$ Department of Urology, Evangelic Hospital, Chair in Geriatrics of the University of Witten/Herdecke, D-58455 Witten, \\ Germany \\ ${ }^{2}$ A.CRO Clinical Research Services GmbH, D-65191 Wiesbaden, Germany \\ ${ }^{3}$ Department of Medical Science/Clinical Research, Dr. R. Pfleger GmbH, D-96045 Bamberg, Germany
}

\begin{abstract}
Introduction \& Objectives: This was a multicenter, non-interventional study performed in urology practices investigating prescribed dosage regimens as well as the efficacy and tolerability of an oral therapy with trospium chloride in patients with overactive bladder $(\mathrm{OAB})$ under routine conditions.

Material and Methods: Naive or insufficiently treated OAB patients in which oral therapy with trospium chloride ${ }^{1}$ was prescribed by the physician were eligible to participate. Dosing and duration of treatment were not predetermined. Core symptoms of OAB, a Quality of Life (QoL) score as well as dosage regimens were assessed at the beginning and at two consecutive visits. Adverse events and withdrawals were documented.

Results: In 4,092 cases pre and post treatment data was available for the evaluation of efficacy; all 4,167 cases were included in the safety analysis. After a mean treatment period of 40 days, all core symptoms of OAB had improved e.g. the median total of micturitions was reduced from 12 to 8 (day) and from 3 to 1 (night). The percentage of incontinent patients dropped from $54.4 \%$ to $29.1 \%$. The proportion of patients requiring incontinence pads was reduced from $47.6 \%$ to $30.1 \%$. The median QoL score had improved from 3 to 1 . Only $20 \%$ of the patients were treated with the standard dose of $45 \mathrm{mg}$ trospium chloride. Nearly $50 \%$ of the patients received $30 \mathrm{mg}$ (or less), and $60 \mathrm{mg}$ to $90 \mathrm{mg}$ were prescribed in $30 \%$ of the cases. There were 300 early treatment withdrawals $(7.3 \%)$ and 54 patients experienced adverse events $(1.3 \%)$.

Conclusions: The distinct majority of OAB patients benefit from flexible dosing of trospium chloride, a compound with an equally favorable efficacy and tolerability profile.
\end{abstract}

Keywords: Overactive bladder, urge incontinence, trospium chloride, anticholinergic.

\section{INTRODUCTION}

Overactive bladder (OAB) is defined as a syndrome of "urgency with or without urge incontinence, usually with frequency and nocturia" [1]. In 2000 the prevalence of OAB was reported to be $17 \%[2,3]$ while higher rates $(20 \%$ in women and $44 \%$ in men) have been published more recently $[4,5]$.

Anticholinergics, such as tolterodine or trospium chloride, constitute a first line pharmacological option in the treatment of an isolated overactive bladder syndrome (OAB). Trospium chloride is an anticholinergic compound with a high affinity to all muscarinic receptor-subtypes and with primarily peripheral properties. In the elderly population especially, the use of trospium chloride appears favorable due to its practical absence of central nervous side effects [6].

*Address correspondence to this author at the Department of Medical Science/Clinical Research, Clinical Research, Dr. R. Pfleger GmbH, D96045 Bamberg, Germany; Tel: +49 9516043 161; Fax: +49 9516043 226; E-mail: Claudia.Neumeister@dr-pfleger.de

${ }^{\S}$ These authors contributed equally to this work.

${ }^{1}$ Trospium chloride coated tablets (Spasmex ${ }^{\circledR} 30 \mathrm{mg}$ TC Filmtabletten), Dr. R. Pfleger GmbH, D-96045 Bamberg, Germany
The results of a recent study in patients with $\mathrm{OAB}$ and benign prostate syndrome have shown that the prescribed daily dosages of trospium chloride largely deviated from the official standard dose of the product which is $45 \mathrm{mg}$ trospium chloride per day [7]. Fixed dosing does not seem to be suitable for all patients. Currently, flexible dosing of antimuscarinic agents has become the strategy of choice to meet the needs of the individual patient [13].

The present non-interventional study was undertaken in $\mathrm{OAB}$ patients focusing on individual trospium chloride doses and their possible adjustments, in order to gain a more complete picture in a larger number of patients.

\section{MATERIALS AND METHODOLOGY}

In total, 4,167 patients were entered into this noninterventional prospective study performed at private urology practices in Germany. Patients received an information sheet and signed a consent form regarding data protection. The only inclusion criterion was the presence of OAB symptoms, which was either previously untreated or insufficiently treated.

The study protocol did not contain any dosing instructions regarding trospium chloride, however, the official dosing schemes as well as contraindications were mentioned in the protocol and reference was also made to the Summary of 
Product Characteristics (SmPC) attached to the protocol. It was further requested that the intended treatment period should not fall below four weeks.

The individual observation forms required to collect the following data at the first visit 1: demography, history, OAB symptoms (micturitions per day/night), and incontinence episodes per week, use of incontinence pads as well as the assessment of the QoL score by asking the patients "How much does your bladder problem interfere with your everyday life?" (5-point ordinal scale ranging from $0=$ "none at all" to $4=$ "very severe"). Furthermore, details of any previous treatment and its tolerability were to be documented, as well as prescribed dosing details regarding trospium chloride. On visit 2, the following was to be recorded: treatment period and applied dosing scheme of trospium chloride, OAB symptoms, incontinence episodes, use of incontinence pads, QoL score, investigator's and patient's assessment of treatment efficacy and tolerability, and any changes of the therapy regimen. On Visit 3, in addition to the issues to be recorded at visit 2 , any adverse events were also to be documented.

Data were entered into the computer and analyzed by SPSS 10 statistical software solely in an exploratory sense.

Prior to study start, the observational study protocol was submitted to an ethics committee (freiburger ethikkommission $\mathrm{GmbH}$ international, Freiburg, Germany). Additionally, in compliance with legal requirements in Germany, the competent authorities were given notice of the study and of participating practices and the official recommendations for the conduct of non-interventional studies were observed $[8,9]$.

\section{RESULTS}

\section{Study Population and Basic Demographic Data}

All 4,167 case reports obtained were entered into the safety analysis. According to the study plan, 75 patients with retrospective documentation or an unclear study period were excluded from further analysis, rendering a baseline population of 4,092 patients.

$63.3 \%$ of the study population were female, $36.5 \%$ were male $(0.1 \%$ missing data). The mean age of the patients was 64.9 years $( \pm 13.7$; median 68 ; min. 14 ; max. 96) and the mean body weight $77.4 \mathrm{~kg}( \pm 13.4$; median 77 ; min. 38 ; max. 178).

\section{History of OAB Symptoms at Baseline}

In the baseline population of 4,092 patients, OAB had been present for "years" in 1,272 of the patients (31.1\%) and for "months" in 2,035 patients (49.7\%). The rest had been diagnosed shortly before the baseline visit.

In $76.7 \%$ of the patients the daily micturition frequency was $>8$ to 15 , and in $17.2 \%$ the micturition frequency was $>15$.

Nightly micturitions were reported by $95.4 \%$ of the patients while $4 \%$ of the patients were unaffected. In most patients $(60 \%)$, the frequency of nightly micturitions was $3-5$.

The majority of patients rated the urgency as "severe" $(45.9 \%)$ or "medium" $(44.3 \%)$, while in about $9 \%$ of the patient's urgency was "mild" or not existent.
2,225 patients $(54.4 \%)$ were affected by incontinence episodes and experienced a mean of $9.7( \pm 10.7)$ per week. 1,946 patients $(47.6 \%)$ used a mean of $14.6( \pm 10)$ incontinence pads per week.

\section{QoL Score Before Treatment}

In the baseline population of 4,092 patients, the median of the QoL score was 3 before therapy start.

\section{Trospium Chloride - Dosing and Treatment Period}

The most frequently prescribed initial daily doses of trospium chloride were $30 \mathrm{mg}(44.4 \%), 45 \mathrm{mg}(20.3 \%)$ and $60 \mathrm{mg}(25.9 \%)$, respectively; $4.8 \%$ of the patients received a higher dose $(90 \mathrm{mg} / \mathrm{die})$ and $3.9 \%$ of the patients a lower dose $(15 \mathrm{mg} / \mathrm{die})$.

Consecutive visit 2 and final visit 3 took place 15 days and 32 days (medians) after visit 1 , respectively.

As depicted in Table 1, administered doses at visit 2 were practically in agreement with the prescription at visit 1 . At visit 3 , administration data showed a decreased proportion of the $30 \mathrm{mg}$ dose while proportions of higher doses $(60 \mathrm{mg}$ and $90 \mathrm{mg}$ ) had increased.

Table 1. Prescribed and Administered Daily Doses of Trospium Chloride (Baseline Population $n=4.092$ )

\begin{tabular}{|c|c|c|c|}
\hline \multirow{2}{*}{$\begin{array}{c}\text { Daily Dose of } \\
\text { Trospium Chloride }\end{array}$} & \multirow{2}{*}{$\begin{array}{l}\text { Prescription } \\
\text { (\%) }\end{array}$} & \multicolumn{2}{|c|}{ Administration Until } \\
\hline & & $\begin{array}{c}\text { Visit } 2 \\
\text { (\%) }\end{array}$ & $\begin{array}{c}\text { Visit } 3 \\
(\%)\end{array}$ \\
\hline $15 \mathrm{mg}$ & 3.9 & 4.1 & 3.4 \\
\hline $30 \mathrm{mg}$ & 44.4 & 44.0 & 35.8 \\
\hline $45 \mathrm{mg}$ & 20.3 & 19.8 & 20.4 \\
\hline $60 \mathrm{mg}$ & 25.9 & 25.7 & 28.0 \\
\hline $90 \mathrm{mg}$ & 4.8 & 4.5 & 6.6 \\
\hline Other & 0.7 & 0.7 & 2.4 \\
\hline no data & -- & 1.2 & 3.3 \\
\hline Total & 100 & 100 & 99.9 \\
\hline
\end{tabular}

\section{Concomitant Medication}

For the treatment of urological symptoms (e.g. benign prostate syndrome), $16.1 \%$ of the patients took alphareceptor blockers, $4.3 \%$ of the patients received 5-alphareductase inhibitors, and $3.5 \%$ of the patients used phytopharmaceuticals, in addition to trospium chloride.

The most common concomitant medications for the treatment of basic diseases (e.g. obesity, cardiovascular diseases, Parkinson's disease) were beta-receptor blockers in $25.3 \%$ of the patients, tricyclic antidepressants in $4.6 \%$ of the patients, and anti-parkinson drugs in $3.6 \%$ of the patients.

\section{OAB Symptoms During Treatment with Trospium Chloride}

At visit 2, a significant improvement of all symptoms was evident, and a further change for the better was achieved by visit 3 . 


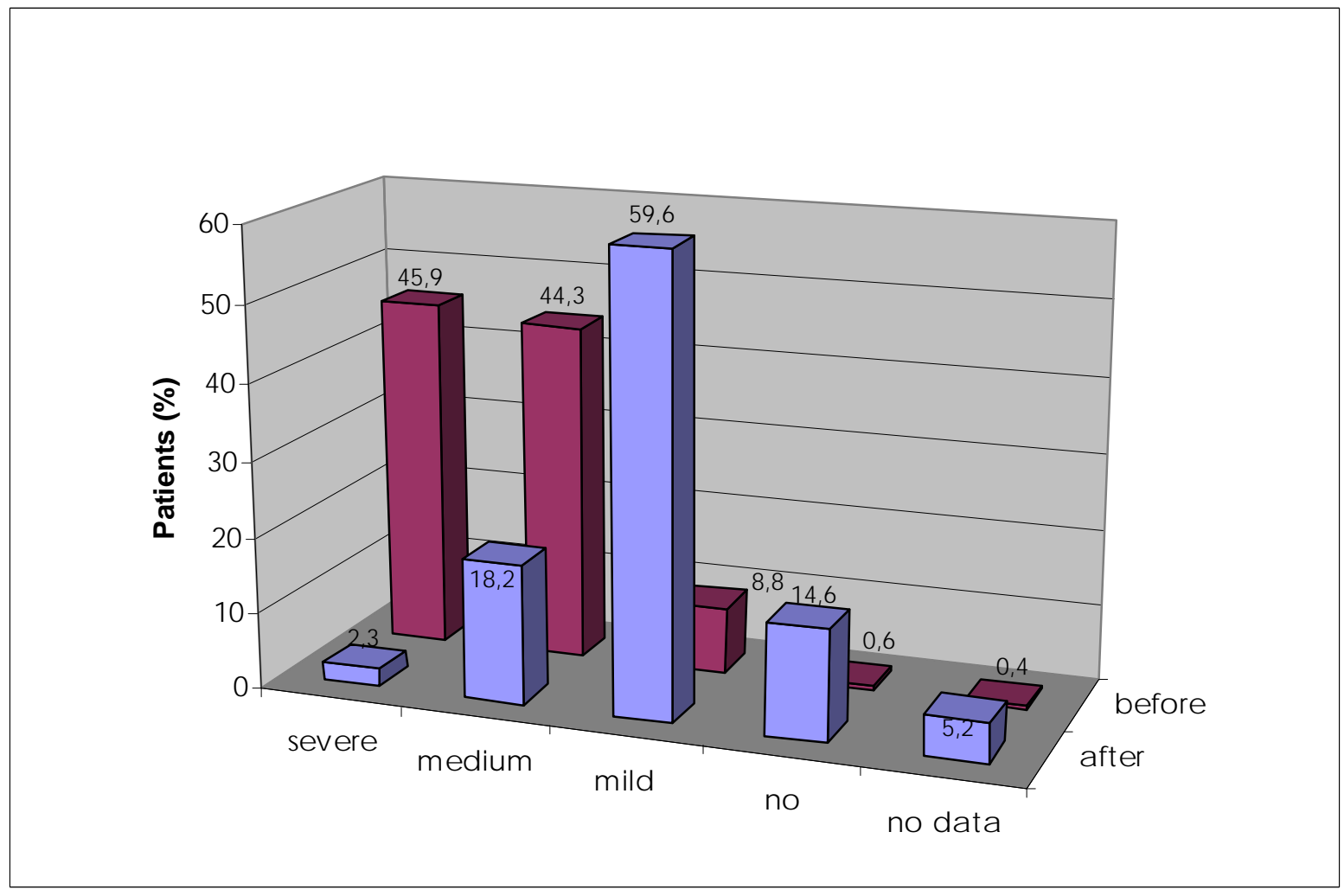

Fig. (1). Degree of urgency before and after therapy with trospium chloride $(n=4,092)$.

At visit 3 , the proportion of patients rating the sensation of urgency as "severe" was reduced from $45.9 \%$ to $2.3 \%$. Concomitantly, the percentage of patients with only "mild" urgency rose from $8.8 \%$ to $51.5 \%$, and the fraction of patients without urgency problems increased from $0.6 \%$ to $14.6 \%$ (Fig. 1).

Concordantly, a clear reduction in micturition frequencies (day and night) was observed. The proportion of patients with more than 10 daily micturitions dropped from $63.7 \%$ to $11.0 \%$, while the fraction of patients with up to 10 daily micturitions rose from $35.9 \%$ to $85.7 \%$. Further, a clear reduction of nightly micturition frequencies was observed (Table 2).

Furthermore, the proportion of patients with incontinence episodes was more than halved from $54.4 \%$ to $21.1 \%$. However, patients who were still affected profited substantially from treatment with trospium chloride as the median of incontinence episodes was reduced from 7 to 4 events per week. Consequently, the average number (median) of incontinence pads used per week was halved by $50 \%$ from 14 pads at baseline to 7 at visit 3 (Table 3 ).

\section{QoL Score}

The positive development of OAB symptoms under treatment with trospium chloride were also reflected by distinct changes in the QoL score (median) which improved during treatment from 3 at baseline to 1 at visit 3 . Details of changes are shown in Table 4.

\section{Rating of Treatment Efficacy}

The general assessment of treatment efficacy by investigators and patients at visits 2 and 3 is shown in Table
5. The ratings reflect a fair degree of satisfaction already at visit 2 after 15 days of treatment. At visit 3, in $84.4 \%$ of the cases the investigators rated the therapy outcome as "very good" or "good", and only in 3.3\% as "poor". The patients' ratings were comparable.

Table 2. Micturition Frequencies Before and During Treatment with Trospium Chloride (Baseline Population $n=4,092$ )

\begin{tabular}{|c|c|c|c|}
\hline \multirow{2}{*}{ Micturitions (n) Per Day } & \multicolumn{3}{|c|}{ Patients (\%) } \\
\cline { 2 - 4 } & Visit 1 & Visit 2 & Visit 3 \\
\hline \hline$<8$ & 5.7 & 26.2 & 41.6 \\
\hline $8-10$ & 30.2 & 50.5 & 44.1 \\
\hline $11-15$ & 46.5 & 18.1 & 9.4 \\
\hline $16-20$ & 14.5 & 3.4 & 1.5 \\
\hline $21-40$ & 2.7 & 0.4 & 0.1 \\
\hline no data & 1.3 & 1.3 & 3.3 \\
\hline Thereof at Night & & & \\
\hline 0 & 4.0 & 9.2 & 14.7 \\
\hline $1-2$ & 27.4 & 64.3 & 69.6 \\
\hline $3-5$ & 59.9 & 22.5 & 10.0 \\
\hline $6-10$ & 7.9 & 1.7 & 0.9 \\
\hline$>10$ & 1.5 & 0.02 & 0.07 \\
\hline no data & 0.6 & 2.2 & 4.7 \\
\hline
\end{tabular}


Table 3. Incontinence Episodes and Pads Used Before and During Treatment with Trospium Chloride (Baseline Population $n=4,092$ )

\begin{tabular}{|c|c|c|c|}
\hline \multirow{2}{*}{ Incontinence Episodes } & \multicolumn{3}{|c|}{ Patients (\%) } \\
\hline & Visit 1 & Visit 2 & Visit 3 \\
\hline yes & 54.4 & 38.4 & 21.1 \\
\hline \multicolumn{4}{|c|}{ Incontinence Episodes Per Week (n) } \\
\hline $1-2$ & 11.7 & 23.4 & 28.8 \\
\hline $3-5$ & 24.6 & 29.2 & 31.2 \\
\hline $6-10$ & 34.0 & 28.8 & 22.9 \\
\hline $11-20$ & 16.9 & 9.5 & 6.9 \\
\hline$>20$ & 7.5 & 3.2 & 2.1 \\
\hline no data & 5.3 & 5.8 & 8.5 \\
\hline $\begin{array}{l}\text { Incontinence Episodes } \\
\text { Per Week (n) (Median) }\end{array}$ & 7 & 5 & 4 \\
\hline $\begin{array}{l}\text { Incontinence Pads Used } \\
\text { Per Week (n) (Median) }\end{array}$ & 14 & 8 & 7 \\
\hline
\end{tabular}

Table 4. QoL Score Before and During Treatment with Trospium Chloride (Baseline Population $n=4,092$ )

\begin{tabular}{|c|c|c|c|}
\hline \multirow{2}{*}{ QoL Score (Median) } & Visit 1 & Visit 2 & Visit 3 \\
\cline { 2 - 4 } & $\mathbf{3}$ & $\mathbf{2}$ & $\mathbf{1}$ \\
\hline QoL Score & \multicolumn{3}{|c|}{ Patients (\%) } \\
\hline \hline 0 & 0.1 & 5.4 & 14.1 \\
\hline 1 & 2.7 & 30.4 & 46.9 \\
\hline 2 & 20.5 & 40.9 & 28.3 \\
\hline 3 & 48.5 & 18.2 & 6.5 \\
\hline 4 & 28.2 & 4.0 & 1.5 \\
\hline no data & $<0.1$ & 1.1 & 2.8 \\
\hline
\end{tabular}

Table 5. Assessment of Treatment Efficacy at Visits 2 and 3 (Baseline Population n = 4,092)

\begin{tabular}{|c|c|c|c|c|}
\hline \multirow{2}{*}{} & \multicolumn{4}{|c|}{ Insessment of Treatment Efficacy } \\
\cline { 2 - 5 } & Visit 2 & Visit 3 & Visit 2 & Visit 3 \\
\hline \hline Very good & 25.9 & 37.0 & 27.1 & 38.8 \\
\hline Good & 45.2 & 47.4 & 41.8 & 45.2 \\
\hline Fair & 21.2 & 9.6 & 21.3 & 9.4 \\
\hline Bad & 6.0 & 2.8 & 7.3 & 3.2 \\
\hline Very bad & 0.6 & 0.5 & 1.5 & 0.7 \\
\hline No data & 1.1 & 2.7 & 1.0 & 2.7 \\
\hline Total & $\mathbf{1 0 0}$ & $\mathbf{1 0 0}$ & $\mathbf{1 0 0}$ & $\mathbf{1 0 0}$ \\
\hline
\end{tabular}

\section{Rating of Treatment Tolerability}

At visit 3, general tolerability of oral treatment with trospium chloride was rated as "very good" or "good" by $90.2 \%$ of the investigators and $87.1 \%$ of the patients (Table 6).

Table 6. Assessment of Treatment Tolerability at Visits 2 and 3 (Baseline Population n = 4,092)

\begin{tabular}{|c|c|c|c|c|}
\hline \multicolumn{5}{|c|}{ Assessment of Treatment Tolerability } \\
\hline & \multicolumn{2}{|c|}{ Investigator (\%) } & \multicolumn{2}{|c|}{ Patient (\%) } \\
\hline & Visit 2 & Visit 3 & Visit 2 & Visit 3 \\
\hline Very good & 33.1 & 40.0 & 31.1 & 38.2 \\
\hline Good & 54.4 & 50.1 & 52.1 & 48.9 \\
\hline Fair & 9.6 & 6.0 & 12.9 & 8.2 \\
\hline Bad & 1.6 & 0.9 & 2.3 & 1.4 \\
\hline Very bad & 0.2 & 0.2 & 0.5 & 0.5 \\
\hline No data & 1.1 & 2.8 & 1.1 & 2.8 \\
\hline Total & 100 & 100 & 100 & 100 \\
\hline
\end{tabular}

\section{Therapy Withdrawals and Side Effects}

Treatment with trospium chloride was prematurely terminated in 300 of 4,092 patients $(7.3 \%)$, thereof in 111 cases $(37 \%)$ due to lacking efficacy, in 94 cases $(31.3 \%)$ due to lack of acceptance by the patient, and in 37 cases $(12.3 \%)$ due to adverse effects.

All in all, evidence of adverse effects was found in 54 cases $(1.4 \%)$ in the observation forms, and were mostly known side effects of trospium chloride such as dry mouth, diarrhea, constipation, gastrointestinal disorders and urinary retention.

\section{DISCUSSION}

Anticholinergic agents are the most common and the most effective drugs to date for the treatment of OAB [8] and other forms of urinary incontinence [9-12]. Once-daily formulations have been developed for several anticholinergic agents in order to improve patient compliance and tolerability [16]; however the negative side of such formulations is that they only allow for fixed dosing. Nowadays, results of randomized, controlled clinical trials as well as open label, flexible-dose studies indicate the advantages of adaptable dosing, which allow a more personalized treatment $[13-15,17]$. This approach considers the individual sensitivity of the patient to the drug as well as the willingness to tolerate a certain degree of side effects. For the selection of an effective dose with minimal side effects, different drug doses should be made applicable [17].

The results of this observational study are in line with the recent developments concerning an individualized drug therapy for patients suffering from overactive bladder. In only $20 \%$ of the cases the daily standard dose of $45 \mathrm{mg}$ trospium chloride was used. In almost $50 \%$ of the cases, $30 \mathrm{mg}$ (or less) were prescribed, but about $30 \%$ of the 
patients received 60 to $90 \mathrm{mg} / \mathrm{die}$, which is above the actual official dose range in Germany. Interestingly, in Austria the regulatory authority has already allowed dose adjustment of trospium chloride ${ }^{2}$ up to $90 \mathrm{mg} / \mathrm{die}$ after considering the individual efficacy and tolerability.

For trospium chloride, several immediate-release formulations with 5 different doses $(5 \mathrm{mg}, 10 \mathrm{mg}, 15 \mathrm{mg}$, $20 \mathrm{mg}, 30 \mathrm{mg}$ ) and 1 extended release formulation $(60 \mathrm{mg})$ are available on the German market, therefore providing various possibilities for dose titration. Additionally, the $30 \mathrm{mg}$ formulation presented here can easily be halved.

Individual adjustment of doses, including the prescription of the higher doses is (a) evidence for the extensive experience with trospium chloride with regard to both efficacy and tolerability, and (b) also in accordance with the recommendations for a personalized drug therapy [9].

Furthermore, the results of this non-interventional investigation in 4,092 OAB patients confirm the recognized therapeutic value of the anticholinergic trospium chloride. The majority of patients noted a meaningful reduction in all $\mathrm{OAB}$ symptoms (less frequency day and night, less urgency, less urge incontinence). Moreover, in $61 \%$ of patients with incontinence symptoms before treatment, complete continence was achieved. It is noteworthy that the aforementioned very positive results in this study were obtained after an average observation period of only 32 days. Therefore, an even higher responder rate may be expected in long-term therapy. Even at higher doses, the generally good tolerability of trospium chloride was not impaired which supports earlier results [7].

\section{CONCLUSION}

The results of this study confirm the therapeutic value of trospium chloride in patients with OAB symptoms. Individual dosing is commonly used in everyday clinical practice as it was shown to take place in just under $80 \%$ of the observed patients.

\section{CONFLICT OF INTEREST}

Wiedemann A - Consultant to Sponsor

Kusche W - Employee of A.CRO GmbH, the contract research organization commissioned with data management and analysis

Neumeister C - Employee of Sponsor

\section{ACKNOWLEDGEMENTS}

The authors wish to thank all contributing urologists in Germany for their valuable cooperation. We thank Anna Wolf for proofreading the manuscript.

\section{REFERENCES}

[1] Abrams P, Cardozo L, Fall M, et al. The standardization of terminology of lower urinary tract function: report from the standardization subcommittee of the international continence society. Neurourol Urodyn 2002; 21: 167-78.

[2] Milsom I, Stewart W, Thuroff J. The prevalence of overactive bladder. Am J Manag Care 2000; 6(Suppl 11): 565-73.

[3] Milsom I, Abrams P, Cardozo L, Roberts RG, Thuroff J, Wein AJ. How widespread are the symptoms of an overactive bladder and how are they managed? A Population based prevalence study. BJU Int 2001; 87: 760-6.

[4] Wennberg A-L, Molander U, Edliund C, Peeker R, Milsom I. A Longitudinal population-based survey of urinary incontinence, overactive bladder, and other lower urinary tract symptoms in women. Eur Urol 2009; 55(4): 783-91. Epub 2009 Jan 13.

[5] Malmsten UGH, Molander U, Peeker R, Irwin DE, Milsom I. Urinary incontinence, overactive bladder, and other lower urinary tract symptoms: a longitudinal population-based survey in men aged 45-103 years. Eur Urol 2010; 58: 149-56.

[6] Rauchenwald M. Die überaktive Harnblase. Der Mediziner 2007; 16(12): 20-2

[7] Wiedemann A, Neumann G, Neumeister C, Kusche W, Schwantes U. Efficacy and tolerability of add-on trospium chloride in patients with benign prostate syndrome and overactive bladder: a noninterventional trial showing use of flexible dosing. UIJ April 2009; (2)2: 1944-5784. Available from: http://www. urotodayintern ationaljournal.com

[8] Abrams P, Anderson K-E. Muscarinic receptor antagonists for overactive bladder. BJU Int 2007; 100: 987-1006.

[9] Schröder A, Abrams P, Andersson KE, et al. Guidelines on urinary incontinence. Europ Assoc Urol 2010. Available from: http://www. uroweb.org

[10] Stöhrer M, Blok B, Castro-Diaz D, et al. EAU guidelines on neurogenic lower urinary tract dysfunction. Eur Urol 2009, 56: 818 .

[11] Andersson KE, Appell R, Cardozo L, et al. Pharmacological treatment of urinary incontinence. In: incontinence. 3rd International Consultation on Incontinence: 26-29 June 2004. Edited by Abrams P, Cardozo L, Khoury S, Wein A. Plymouth, UK: Health Publication Ltd 2005; 809-54.

[12] Scottish Intercollegiate Guidelines Network. Management of urinary incontinence in primary care. Royal College of Physicians 2004. Available from http://www.sign.ac.uk

[13] Chapple CR, Rosenberg MT, Brenes J. Listening to the patient: a flexible approach to the use of antimuscarinic agents in overactive bladder syndrome. BJU Int 2009; 104: 960-7.

[14] Dmochowski RR, Peters KM, Morrow JD, et al. Randomized, double-blind, plazebo-controlled trial of flexible-dose fesoterodine in subjects with overactive bladder. Urology 2010; 75(1): 62-8.

[15] Wyndaele, J-J, Goldfischer ER, Morrow JD, et al. Patientoptimized doses of fesoterodine imoprove bladder symptoms in an open-label, flexible-dose study. BJU Int 2011; 107(4): 603-11.

[16] Rovner ES, Wein AJ. Once-daily, extended-release formulations of antimuscarinic agents in the treatment of overactive bladder: a review. Eur Urol 2002; 41: 6-14.

[17] Michel MC, Staskin D. Understanding dose titration: overactive bladder treatment with fesoterodine as an example. Eur Urol Suppl 2011; 10: 8-13.

${ }^{2}$ Trospium chloride coated tablets (Inkontan ${ }^{\circledR}$ 15/30 mg Filmtabletten)

Pharm. Fabrik Montavit Ges.m.b.H., A-6060 Absam/Tirol, Austria

Received: July 22, 2010

Revised: April 28, 2011

Accepted: May 5, 2011

(C) Wiedemann et al.; Licensee Bentham Open.

This is an open access article licensed under the terms of the Creative Commons Attribution Non-Commercial License (http://creativecommons.org/licenses/by$\mathrm{nc} / 3.0 /$ ) which permits unrestricted, non-commercial use, distribution and reproduction in any medium, provided the work is properly cited. 